\title{
Balancing scientific and impact recognition on agriculture research and development in developing country
}

\author{
Catur Hermanto*, and Sudarmadi Purnomo \\ East Java Assessment Institute for Agriculture Technology - Indonesian Agency for Agriculture \\ Research and Development
}

\begin{abstract}
People discuss very seriously on an issue about the connection between research and commercialization, and the science and impact at the end. Some theories dichotomize both ends, i.e.: Death Valley, technology readiness level, research and commercialization, science and technology, and so on. Gap between scientific and impact should not be a big issue since research might only result in science, not technology, technology could be composted from several sciences, and not every technology goes directly to commercialization. However, efforts are needed to encounter the issues. On Agriculture, a long journey/sequence on Research and Development (R\&D) might also contribute to the gap between scientific and impact recognition. Balancing could be done through a research consortium that able to shorten the research sequence, strengthen the concept, redesign the R\&D concept, and conduct commercial research and the involvement of the private.
\end{abstract}

\section{Introduction}

Research is expected to produce scientific information that can support subsequent scientific activities. However, the output of research does not stop at scientific information, but can also be used further to produce a wider impact (tangible and/or intangible). Research that is not designed strongly and continuously, will usually stop at the scientific output which sometimes stands separately. In this context, the road to achieving research impact becomes longer and complicated. A more comprehensive and integrated research approach is needed to gain a balance between scientific results and the impact of one/a series of research.

Research impact and parameters are important in obtaining a balance between the scientific information, benefit, and impact produced through the research process. This is very important for the development of agricultural science, which could produce future challenging solutions, which will increase because of the increase in population, change of climate, and degradation of the ecosystem. An econometric effort has been abundant for devoting the analyses of the agricultural investment in agricultural research and the effect on productivity. Midmore [1] provides a review that a research performance impact is proportional to the flow of scientific information, and the policymakers perceive the impact

* Corresponding author: mas caturhermanto@yahoo.co.id 
to be too little, and their needs are less targeted. The contribution of agricultural research outputs discrepancy with the way they reach and meet the farmers' needs has motivated the rise of impact evaluation by using a participatory method, which has been applied in most low-income countries. But, cognitively this approach is expensive and complex.

As consumer preferences often change rapidly, hence the agriculture product variety change cycle is also being accelerated, but the real condition shows that research and development institutions are under unprecedented pressure. As the product variety grows and the product portfolio expands, updating existing products will add a heavy burden to research and development institutions. Meanwhile, in new challenges in the 21 st century, research and development units are still following the organizational model of the 20th century, a model that was not designed for today's needs which goes beyond speed and wide interconnecting network that move without limit in all parts [2]. The traditional component-based approach is not sufficient anymore in the digital and electronic era that has already been completely integrated with the hardware.

This paper is objected to find tools and approach to balance scientific and impact of research in agriculture through reviewing relevant literature and personal opinion/ideas.

\section{Challenge of agriculture research in developing country}

In the coming decades, pressures on food sufficiency and agricultural business are difficult to be managed by farmers, markets, input providers, or research institutions if the agribusiness is not different from today. The approach is focused primarily on making gradual improvements to solve the problems that arise due to biological, physical, and some human intervention.

Food systems are vast, complex, and interconnected. "Evil" with problems connected to many different factors which are difficult to be identified or define will need different approaches to find solutions which may only be obtained if it is explored outside the traditional way of the food and agricultural systems. To get a better view to optimize the food and agriculture system, including those that affect them, a broader perspective is needed. This perspective needs to be reframed with a more suitable tool to identify and manage the things that are important in the intervention of a more efficient, resilient, and sustainable system. There is a need for scientific innovations that can improve the ability of food science and agriculture.

An approach to the system is needed in understanding the form of interaction between various foodstuffs and agriculture. Then it is can be utilized to improve the efficiency, resilience, and sustainability of the system as a whole. Progress towards achieving the ultimate goal can only exist when scientific groups began to combine science, technology, human behavior, economics, and policy more methodically into biophysical and empirical forms. This approach is needed to accurately measure changes in resource usage, market effects, and environmental responses. This approach can also determine the benefits of Attention to the interactions between these systems is urgently needed to obtain comprehensive solutions to challenges that jeopardize the security and competitiveness of food and agriculture.

Problem-based collaboration between disciplines needs to be done because not everyone will be professionally interested in other fields of science. Such a transition will require learning to work in a transdisciplinary team. To attract and engage researchers from various disciplines to collaborate effectively on agriculture and food issues will need incentives for such collaboration. The use of a meeting approach in a certain place will also facilitate new collaborations that are difficult for researchers working in different disciplines to do. The transdisciplinary problem-based collaboration will lead to the involvement of a variety of new stakeholders and partners and will benefit the agriculture and food sectors. Leadership 
is the key to success in forming a science team, as scientific directors require specific skills, including open-mindedness to multiple perspectives, the ability to big concepts and fantasize, and most importantly a talent for bringing people together for a common goal. These qualities do not always come naturally to scientists, which is why providing professional development opportunities to encourage leadership in a transdisciplinary model is important.

The development and validation of sensors and biosensors which precise, accurate, and field-applicable will make it easier to quick detection and the ability to monitor across a wide range of food and agricultural disciplines. Advances in science and technology in the fields of materials science, microelectronics, and nanotechnology will enable the creation of new nano and biosensors to continuously monitor environmental stimuli, biotic and abiotic stresses. Future sensors will be able to revolutionize the ability to detect disease before symptoms develop in both plants and animals, to identify pathogenic substances before they enter the food distribution chain, and to monitor and make timely decisions. Make initiatives for more efficient use of existing sensing technologies and develop new sensing technologies in all fields of agriculture and food. The use and incorporation of data science, software, and systems models will enable an advanced analysis to manage agriculture and food systems. In agriculture and food systems large amounts of data are collected, but there is no proper tool to use the data effectively.

To go further on discussing what the challenge on Agriculture Research, especially in developing countries, we need to describe on how does the activity usually running. Research in agriculture is very different from research in the industrial or manufacturing sector. Research in agriculture involves the sciences of biology, chemistry, and physics, and is strongly influenced by environmental conditions in the form of climate, soil, vegetation, and biota that are on and under the soil surface. In this context, research results in agriculture are specifically influenced by biological and environmental factors. The many factors that must be considered, lead to a research model which involves many parties with diverse approaches.

Researches that was conducted for varietal engineering on rice, for example, involved so many research and actors, namely genome sequencing [3,4], breeding for water pressure [5], breeding for pests [6,7], pest evaluation [8,9], and related activity in varietal dissemination and development that were done by several institutions. With such a pattern, agricultural research follows a pyramid pattern, from basic, intermediate, and applied research activities or commercialization. The situation is very much different when entering the industrial sector. For short, from observation in the field, Table 1 describes differences between research on Agriculture and research on industry.

Table 1. Description of the differences between research in agriculture and industry

\begin{tabular}{|c|c|c|}
\hline Topic & Research on Agriculture & Research on Industry \\
\hline The sequence & $\begin{array}{c}\text { Long and involves many } \\
\text { major of sciences }\end{array}$ & Relatively short \\
\hline Actor & $\begin{array}{c}\text { Many actors, many } \\
\text { agencies }\end{array}$ & Close in the industry \\
\hline User & Farmer & The industry \\
\hline Control & Not particularly connected & $\begin{array}{c}\text { All sequences are under the } \\
\text { control of the industry }\end{array}$ \\
\hline Scientific recognition & Mostly published & Mostly private or patented \\
\hline Impact recognition & Not necessarily tangible & Tangible and commercial \\
\hline
\end{tabular}




\section{How to balance science and impact}

In this paper, it is stated that a multi-dimensional assessment of technology readiness is needed to obtain a good understanding of the development and implementation of technology assembly. How good is technological progress? How ready is the existing market? Has the legal aspect received good attention? Does society will accept the technology? How should users integrate new technologies into their current activities? These are the questions that need to be addressed by a balanced approach between science and technology, where scientific information milling about rather than benefits of its impact.

\subsection{Assessing scientific and impact of research on agriculture}

Research on agriculture is a long series of work, started from genetic collection, morphological, ecological, and molecular identification of genetic material, breeding, cultivation, postharvest physiology and processing, till marketing tools, approaches and systems. Scientific output of such researches can be material genetic collection, DNA collection, genetic sequent information, primer, variety, agronomic and postharvest technology, and marketing system and information. One topic of research or a research on particular crop in agriculture resulted in huge number of scientific output in form of scientific paper, prototype, formula, ministrial decree of variety, patent, end so on. Productivity of a research is measured from how big and how god are the scientific output. Nowadays, there are tools to assess the quality of scientific output of a research based on paper citation, licence of patent, adoption of technology, and demand of primary products. One of the tools to measure the maturity of research output/technology is technology readiness level (TRL). In Indonesia, it was adopted by Ministry of Research and High Education in the decree no 42/2016 [10]. Technology readiness level (TRL) is a recent conceptual tool in measuring the new development of agricultural technologies, to measure its development complexities and technology implementation. In the decree, the maturity research output is measured in numeric scale of 1-9, in which one level to another is related and forms the base for the next level.

However, as many have noted, the new technologies development is not linear and it cannot be captured only by material technology readiness $[11,12]$. The flow of thought about the level of readiness on the existing technology packages often uses a straight timeline/linear, while it is actually not [13]. Markets are required by the new technology in agriculture, and the TRL does not necessarily coincide with the Market Readiness Levels (MRL) [12,13]. In addition, might create conflict with the regulation, organizational, societal, and political understanding [14]. Even though the new technology has high TRL and MRL value, times do not mention what and how the new technology should be adopted by the user [15] as well as when users took it into the sphere of everyday practice in their socio-technical structure. Therefore, to make a better understanding of if new technology can be implemented and its reason why (cannot), this article aims to examine a set of concepts and methodologies for agriculture technology readiness level assessment. This includes 5 important aspects of the parameters which are: Technology (material) readiness; Market readiness; Regulation readiness; Organizational readiness; and level of acceptance readiness (social regulation). Hence, Vik et al. [16] expanded the TRL into balanced readiness level (BAL) by combining the Market Readiness Level (MRL), Regulation Readiness Level (RRL), Acceptance Readiness Level (ARL), and Organizational Readiness Level (ORL). Vik et al. [16] used the method to illustrated in 36 new agricultural technologies and the development of technology for virtual agricultural markets. Vick's article present method for assessing the balance of the new technology readiness level and 
methodology to describe and categorize agricultural technologies in the future. Therefore, the development and exploration methodology of a balanced readiness has also functioned as the new way to measure a new technology development approach. The structure of the design is as the following: first, data and method presentation; second, reviewing the literature on technology readiness level, third, level investigation of market readiness; and the level of community readiness. Vick's concept has gradually increased and is currently used worldwide in various organizations [17].

Measuring the status of resulted technology is not the final step of research. The technology should be sent to massive implementation, production and commercialization to gain impact. Impact of research in agriculture can be assessed economically (economic raising of farmer or country), socially (massively adopted due to fit to the social situation of the community), and environmentally (safe for environment). Reed et al. [18] reviewed type for research impact evaluation, namely: a. experimental and statistical methods, b. system analysis methods, c. textual, oral and arts-based method, d. indicator-based approaches, and e. evidence synthesis approaches. Economic impact of research on agriculture is usually measured based on return of investment, value of farmer exchange, crop production elevation, etc.

\subsection{Shorten the research sequence}

The platform for innovation is seen as a promising arena for encouraging a paradigm shift in agricultural research for development [19,20,21]. Through facilitating interaction, negotiation, and collective action between researchers, farmers, and other stakeholders, communities can contribute to a more integrated system of innovation needed to achieve greater and sustainable impacts in agricultural development.

When facilitating interaction and engagement, communities can encourage the 'capacity to innovate' systemic by stakeholders to 1 ). continue to identify and prioritize problems and opportunities in the dynamic environment in which they are located, 2). taking risks and experimenting with socio-technical options and switching between options, 3). mobilizing resources and form joint support around promising possibilities, 4). connecting with other people or businesses to disseminate knowledge and information to support the process of change, and 5). coordinating and collaborate with other parties to achieve collective and integrated action.

Facilitating collaboration and interaction in networks between farmers, extension workers, researchers, policymakers, and other stakeholders in the agricultural system by providing a place for learning, experimentation and negotiation shorten the meandering process of research performance in achieving user benefits. Continuous stakeholder involvement in explaining and describing the problem, also looking for innovation to solve the problem is considered important, for three reasons. First, different stakeholder groups can give different views on biophysical, technological, and institutional aspects, and what types of innovations are technically feasible, economically feasible and socio-culturally, and politically acceptable also capability in the information access [22]. Second, stakeholder groups become aware of their fundamental interdependence and the need for integrated action to overcome their constraints and achieve their goals [23]. Third, stakeholder groups are more likely to support specific solutions when they have become part of the decision-making process [24].

Such innovation systems require a fundamental restructuring on the production systems, supply chain, management, policy, monitoring and evaluation, and decision-making processes. Previous experience shows that through the process of formation and reformation, which are an institution, actors and organizations tend to be locked into a static 'regime' of policies, technology, routines, norms, protocols, incentive structures, values and 
co-opted by regulations. Therefore, Schut et al. [25] commented that the successful implementation of the innovation system requires changes in the governance of agricultural research and development institutions.

\subsection{Strengthen research concept}

The relationship between social change and technological developments in agriculture is very important, but for the most part, it has not been well studied. However, renewed interest in sustainable food intensification, food security, and environmentally friendly agriculture has led to renewed interest in studying technology from a community perspective.

The good relationship between rural development and agriculture as well as technological change makes it indispensable in the perspective of innovation and entrepreneurship as well as analysis, methodologies, and tools for assessing new technologies. What will it take to move from discoveries embodied in scientific information to technologies that can be implemented? What do market participants, funding, organizations, and consulting services need when assessing new ideas and products coming to market? What factors are important in the development and application of new agricultural technologies? This is a list of methodological questions for a balanced assessment of the applicability of each segment in its contribution to a food and agriculture system.

\subsection{Research at commercial scale}

Nowadays, agriculture is the largest business and an important source of income in the world. One-third of the world's population who are still actively working earn income from agriculture. It is, however, agriculture in developing countries face serious problem of land ownership and farming scale. In Asia and Africa, millions of small-scale and subsistence farmers, herders, fishermen, and indigenous peoples produce most of the food consumed worldwide, in many cases on very little land. Over the past few decades, international, as well as public and private agricultural research often regard subsistence and small-scale farmers as a lagging "phase-out model" compared to the pre-industrial production era. For more than 50 years, "grow or die" has been the principle of progress by socialist and capitalist, with only very little difference. A wide belief is that only large economic units can achieve competitive productivity gains through modern and rational cultivation methods, especially with chemical inputs and the use of machinery. Increases in global productivity were deemed necessary to feed the world's rapidly growing population. For this reason, it is necessary to continue building research ideas that can provide commercialscale farming guidelines when on-farm, feasible when entering an industrial scale, and safe. The land ownership situation may unable us to do land consolidation. Idea to conduct management consolidation maybe more suitable. For food crop farming in Indonesia, farmer use to unify into farmer union (Ind.= kelompok tani). It is one of approach to reach minimum scale of farming management, and at the same time to facilitate research at commercial scale.

\subsection{Research consortium}

With such mentioned problems, it is really difficult to balance scientific and impact recognition of agriculture research in developing countries. A research program needs to accommodate such huge actors for research and development, wide topic of interest, long series of program, and very big spend of control. Conduct research program in a consortium 
could be the best way to arrange focus of the research and dissemination/development, accommodate many actors, delineate task/job, and frame particular topic of interest. Research consortium can be done internally or cross organization/country. There many example of international research consortium, namely: Indonesia and Malaysia on education (https://elib.its.ac.id/conf/imrcs/?p=91), African Economic Research Consortium (https://aercafrica.org/), Japan International Academi Forum (https://iafor.org/dvteam/research-consortium-for-the-sustainable-promotion-ofinternational-education-recsie-japan/), and so on.

\section{Conclusions}

- Research on Agriculture in developing countries have very broad topic, involve many actors, wide spend of control, most of the actor publish scientific paper, but the impact is difficult to measure, and not necessarily tangible;

- Balance readiness level described in the Vick's article is a very good tools to assess research output, and bring the output into commercial development, which is combining (1) TRL - level of technological readiness; (2) MRL - market readiness level; (3) RRL - level of regulatory readiness; (4) ARL - acceptance readiness level; and (5) ORL level of organizational readiness;

- Research consortium is very good approach to balance the scientific and impact recognition. The approach can strengthen the research concept, shorten the line, involve many relevant actors, and conduct the research at commercial scale.

\section{References}

1. P. Midmore, J. Agric. Econ. 68, 3, 611-631 (2017)

2. National Academies of Sciences, Engineering, and Medicine, Science Breakthroughs to Advance Food and Agricultural Research by 2030 (The National Academies Press, Washington DC, 2019).

3. M.A. Budiman, Construction and characterization of a BAC library of Oryza sativa L. ssp. japonica cv. Nipponbare for genomic studies (1999)

4. T. Sasaki, B. Burr, Curr. Opin. Plant Biol. 3, 138-141 (2000)

5. A. Hairmansis, Supartopo, B. Kustianto, Suwarno, H. Pane, J. Penelit. dan Pengemb. Pertan. 31, 1, 1-7 (2012)

6. S. Dixit, U.M. Singh, A.K. Singh, S. Alam, C. Venkateshwarlu, V.V. Nachimuthu, S.Yadav, R. Abbai, R. Selvaraj, M.N. Devi, P.J. Ramayya, J. Badri, T. Ram, J. Lakshmi, . Lakshmidevi, J.V. LRK, A.P. Padmakumari, G.S. Laha, M.S. Prasad, M. Seetalam, V.K. Singh, A. Kumar, Rice. 13, 29, doi:10.1186/s12284-020-00391-7 (2020)

7. J. Hu, C. Xiao, Y. He, Rice. 9, 30, doi:10.1186/s12284-016-0099-0 (2016)

8. A. Nasution, N. Usyati, Observation of local rice varieties resistance to blast disease (Pyricularia grisea) in the greenhouse, in Prosiding Seminar Nasional Masyarakat Biodiversity Indonesia, 1, 1, 19-22 (2015)

9. M. Yadav, R. Prasad, R. Prasad, J. Entomol. Zool. Stud. 8, 2, 1510-1514 (2020)

10. Kementerian Riset, Teknologi dan Pendidikan Tinggi, Peraturan Menteri Riset Teknologi dan Pendidikan Tinggi Republik Indonesia Nomor 42 Tahun 2016, tentang Pengukuran dan Penetapan Tingkat Kesiapterapan Teknologi (2016)

11. R. Hasenauer, A. Gschöpf, C. Weber, Technology readiness, market readiness and the triple bottom line: an empirical analysis of innovating startups in an incubator, in 
2016 Portland International Conference on Management of Engineering and Technology (PICMET) (pp. 1387-1428) (2017)

12. D. Dent, B. Pettit, Technology and Market Readiness Levels, Retrieved 12.07.2020, https://www.dentassociates.co.uk/wpdivi/wp-content/uploads/2015/09/Technologyand-Market-Readiness-Levels.pdf (2011)

13. S.S. Hjorth, A. Brem, Sustainability. 8, 1152, 2-16 (2016)

14. P.H. Kobos, L. Malczynski, L.T.N. Walker, D.J. Borns, G.T. Klise, Technol. Forecast. Soc. Change. 137, 5, 211-225 (2018)

15. M. Schut, M. Sartas, C. Leeuwis, G. Thiele, Scaling Readiness: assessing and accelerating scaling of innovations (2019)

16. J. Vik, A. M. Melås, E. P. Straete, R.A. Søraa, Technol. Forecast. Soc. Change. 169, 120854, 1-9 (2021)

17. CloudwatchHub. A Brief Refresher On Technology Readiness Levels (TRL), Available at: https://www.cloudwatchhub.eu/exploitation/brief-refresher-technologyreadiness-levels-trl 2020 (2019)

18. M.A. Reed, M. Ferre, J. Martin-Ortega, R. Blanche, R. Lawford-Rolje, M. Dallimer, J. Holden, Res. Policy. 50, 4 (2021)

19. C. Leeuvis, Communication for Rural Innovation: Rethinking Agricultural Extension (Blackwell Pbl, Third edition, John Willey and Son, 2013)

20. M. Sartas, M. Schut, C. Proietti, G. Thiele, C. Leeuwis, Agric. Syst. 183 (2020)

21. M. Schut, L. Klerkx, M. Sartas, D. Lamers, M.M. Cambell, I. Ogbonna, P. Kaushik, K. Atta-Krah, C. Leeuwis, Expl. Agric. 52, 4, 537-561 (2016)

22. C. Leeuwis, M. Schut, A. Waters-Bayer, R. Mur, K. Atta-Krah, B. Douthwaite, Capacity to Innovate from a System CGIAR Research Program Perspective (CGIAR Research Program on Aquatic Agricultural Systems, Program Brief: AAS-2014-29, 2014)

23. L. Messely, E. Rogge, J. Dessein, J. Rural Stud. 32, 0, 400-410 (2013)

24. A. Neef, D. Neubert, Agric. Human Values. 28, 2, 179-194 (2011)

25. M. Schut, J. Kamanda, A. Gramzow, T. Dubois, D. Stoian, J.A. Andersson, I. Dror, M. Sartas, R. Mur, S. Kassam, H. Brouwer, A. Devaux, C. Velasco, R.J. Flor, M. Gummert, D. Buizer, C. McDougall, K. Davis, S. Homann-Kee Tui, M. Lundy, Exp. Agric. 55, 4, 575-596 (2018) 